\title{
Poesia e infância: o corpo em viva voz
}

Angela Fronckowiak

Resumo: Neste artigo busco problematizar a possibilidade desafiadora, colocada à escola da infância, de perceber o vínculo da leitura de poemas com sua potência enquanto experiência poética que pode ser conquistada em viva voz por um corpo que sente. No momento em que, no cenário educacional brasileiro, discute-se o currículo das escolas de Educação Infantil, o texto defende, a partir dos aportes teóricos da imaginação criadora em Gaston Bachelard; da pedagogia poética em Georges Jean; da performance vocal em Paul Zumthor; e da experiência em Walter Benjamin, a abordagem da literatura não como área do conhecimento ou campo disciplinar, mas como linguagem que emerge da corporeidade.

Palavras-chave: infância; experiência poética; educação infantil; poesia; literatura.

Poetry and childhood: the body in live voice

Abstract: This article seeks to discuss the challenging possibility, placed to the childhood school, of perceiving the bond of the poems reading with its strength as a poetic experience that can be conquered in live voice by a body that feels. At the moment in which, at the Brazilian educational scenario, the organization of the elementary schools curriculum has been discussed, the text defends, based onthe theoretical framework of Gaston Bachelard's creative imagination; on the poetic pedagogy in Georges Jean; on Paul Zumthor's vocal performance and on Walter Benjamin's experience, the approach to literature not as a knowledge area or a subject matter, but as language that emerges from corporeality. Key words: childhood; poetic experience; childhood education; poetry; literature.

Carrego meus primórdios num andor.

Minha voz tem um vício de fontes.

Eu queria avançar para o começo.

Chegar ao criançamento das palavras.

Lá onde elas ainda urinam na perna.

Antes mesmo que sejam modeladas pelas mãos.

Quando a criança garatuja o verbo para falar o que não tem.

Manoel de Barros - Livro sobre nada

Professora do Departamento de Letras da Universidade de Santa Cruz do Sul - RS. acf@unisc.br 
Era uma vez uma professora que gostava de crianças, de poesia e dos alunos grandes com quem convivia na universidade. Estes, pouco confiantes no poder de suas vozes e de suas intuiçôes leitoras, se negavam a ler em voz alta até mesmo trechos em prosa, já que os poemas, não raro, eram considerados leitura difícil e inacessível. "Será assim também na infância da palavra, antes de serem modeladas por mãos de escola?" - ela se indagava.

E havia um grupo de crianças. Elas tinham entre 3 e 6 anos e, como uma "turma" de Educação Infantil de uma escola iluminada pelo sol, cheia de verde, de pátio onde podiam andar e correr, ouviam música, inventavam histórias, modelavam argila, pintavam em folhas grandes e comungavam juntos espaços que eram de todos.

E essa que fui eu escolheu dizer poemas para as crianças não alfabetizadas dessa escola uma vez por semana durante dois anos. Eu gostava de espiá-las experimentando a poesia, saboreava com elas o poético ${ }^{1}$ de forma lúdica, barulhinho monocórdio de fonte: igual sempre diferente. Fazendo isso muito tempo, com a delicadeza de quem des-cobre os princípios, eu criançava, inventando jogos de brincar palavras, ficcionando jeitos de magicar a vida, a minha, num andor. Às vezes, pares de olhos não pareciam muito interessados naquilo que os corpos atentos demonstravam ouvir. Eu refletia sobre essas contradiçōes.

Julgando que conhecia o que buscava, mas sem nem imaginar o que ia encontrar, eu me inventei pesquisadora ${ }^{2}$. E estive com mais crianças, explorei novos poemas, e outros, e repeti a leitura de alguns tantas vezes quantas foram solicitadas, entregando ao ler um sentir-pensar silencioso. Algo lento se fazia em mim.

E era uma vez uma pesquisadora a quem sugeriram que contasse, para outras gentes adultas e sérias e muito ocupadas, mas igualmente crianceiras, aquilo que tinha encontrado. "Mas não há novidade em dizer que nesses encontros entrevi o humano brincando a poesia!" - pensou, pensei. Depois, avançando lá para o começo de quando o que eu vivera não era palavra, garatujei o que ainda não sabia que sabia. Ficou assim:

Brincar o corpo que ouve e ficciona - o que não se ensina e se aprende com a poesia

O grupo de crianças da escola tinha acabado de ouvir o poema "Serenata", de Capparelli (1989, p.76):

I. A palavra "poético" deriva do verbo grego poiein e seu significado está associado a "criar", "fazer" através da linguagem.

2. Experiência oportunizada pelas pesquisas Poesia e infância: a pedagogia poética de Georges Jean e Experiência poética e aprendizagem na infância, ambas financiadas pelo Edital FAP (Fundo de apoio à pesquisa) da UNISC e pelo Edital MCT/CNPq I5/2007 - Universal - Faixa A durante os períodos 2003/2004 e 2006/2009 respectivamente. 
Miau, miau, miau

queremos mingau

queremos mingau

Mia o gato no telhado
mia o gato no varal
mia o gato na bacia
mia o gato no quintal
Miau, miau, miau
queremos mingau
queremos mingau
Mia o gato no xadrez
Mia o gato no hospital
mia o gato na coxilha
mia o gato musical
Miau, miau, miau
queremos mingau
queremos mingau

$\mathrm{Na}$ leitura valorizei o efeito sonoro ${ }^{3}$ imprimido ao texto, melopeia ${ }^{4}$ (Pound, [198-]; 1988) que reverbera a musicalidade de uma exótica composição felina. A um só tempo, poema e leitura foram uma experiência miada em viva voz.

3. No poema, a percepção sensória da palavra "serenata" é evocada em muitos procedimentos compositivos: I) o paralelismo gerado pela repetição de "mia o gato", ao longo da segunda e quarta estrofes, evolui para o ritornelo - uma forma especial de paralelismo em que as repetições se fazem integralmente não só sob o aspecto da ideia, mas também no do(s) vocábulo(s) que a expressa $(m)$ : isso acontece na repetição da primeira estrofe ao longo do texto; 2) o ritornelo, nesse poema, configura-se como estribilho, já que o conjunto dos versos que compõem a primeira estrofe é repetido integralmente, reforçando a melodia; 3) o poema é composto, com exceção das seis sílabas poéticas do primeiro verso do estribilho, só por redondilhas (facilmente memorizáveis do ponto de vista sonoro): menores no estribilho e maiores na segunda e quarta estrofes; 4) as rimas externas alternadas "varal/quintal" e "hospital/musical" são, do ponto de vista sonoro, consoantes. Essa identidade de sons finais semelhantes a partir da tônica extrapola a simples correspondência rímica dos versos, na medida em que reforça a onomatopeia - reprodução do miado dos gatos - já percebida no poema. Note-se que o "al" final dessas palavras realiza-se foneticamente como "au" na linguagem oral, retomando a única rima do estribilho: "Miau, miau, miau / queremos mingau/ queremos mingau".

4. Para Ezra Pound, literatura é linguagem carregada de significado até seu mais alto grau. Isso ocorre por meio de três procedimentos: a melopeia, a fanopeia e a logopeia. Peia, que entra na composição dos três vocábulos propostos, deriva do verbo grego poiein e seu significado está associado a "criar". Mélos, fanos e logos vinculam-se, respectivamente à melodia, à imagem e à ideia. 
Houve silêncio e foi em silêncio que as crianças viram. E como sei que elas viram? Seus olhos se distanciaram de mim, que era seu livro vivo, e seus corpos - presentes e distraidamente atentos - iniciaram um passeio espontâneo de quatro-apoios pelo tapete, repetindo o miado da gataria e transformando em imagem-corpo a sonoridade acolhida. Num instante estavam lambendo patas, ronronando, esfregando os focinhos no peito, se espreguiçando no tapete, ágeis e elásticos. Ali, diante de minha voz - potência de uma cena iniciada -, moviam-se os mais diferentes gatos, nas mais diversas posiçôes, dizendo: "miau, miau, miaul queremos mingaul queremos mingau”. Depois, o longo exercício de experimentar uma percepção de gato - cada qual a sua - cansou a bichanada, e as crianças voltaram novamente à roda, dispostas a conversar:

- Vocês sabem o que é uma serenata? (eu)

- É um tipo de música! (Daniel, 4 anos)

- Equando é que a gente ouve essa música? (eu)

- No casamento! (Mateus, 5 anos)

- Ora, é quando a gente tá muito feliz! (Bianca, 4 anos)

Pela primeira vez, tive certeza de que a imagem, fanopeia instigada pela leitura dos versos, não advinha diretamente deles, nem representava as palavras do poema, assim como não copiava o real projetado pelo texto. As crianças tinham desfrutado de uma espécie de brincadeira cujo divertimento forjara um processo corporal. Mas o que tinham lido a partir da minha leitura?

A tentativa de definir a palavra "serenata" vinculava-se mais à experiência corpórea assumida durante a audição do que à necessidade de racionalização. Da alquimia poética ${ }^{5}$ proporcionada pela escuta do poema não adveio uma narração discursiva fiel aos sentidos do texto. Não foi isso que presenciei nas manifestaçôes por meio da linguagem corpórea (a gestualidade e a mímica), nem nas expressas em linguagem verbal (as respostas).

Ambas as situações indicaram que eu não estava diante de representações do poema, mas de um modo ficcional de descrever um processo, simulando uma invenção não linear e criadora. E, embora não acessassem, ainda, a extensão do conteúdo semântico da palavra serenata, não agregando à ideia da composição

5. Com este conceito Georges Jean ([199-]) enfoca três aspectos simultâneos da leitura que a criança vivencia no momento da audição poemática: a instrumentação verbal (percepção da musicalidade do poema advinda, principalmente, das combinações geradas pelas rimas, pausas e figuras de efeito sonoro que o poema apresenta); a poesia no corpo (prazer muscular proporcionado pela escuta/leitura do poema, que se exterioriza pelo uso da voz - aparelho fonador - mas que permanece no corpo, intensificando a educação sensível) e, finalmente, a imaginação (percepção de imagens, às vezes por analogias, que a audição poética permite à criança a partir da palavra viva projetada pelos poetas). 
melódica o fato de ser executada à noite, ao sereno, a serenata é, como disseram, "um tipo de música".

Ou seja, as crianças moviam-se dentro de um horizonte próximo de significação. Havia ainda a singularidade de que, do mesmo modo como os gatos repetem a cantilena de mios na busca de conquistar sua necessidade de alimento, no poema, o que pode ser metáfora de serenata, o seresteiro repete a serenata para conquistar, através da música, a felicidade do amor da amada. Por isso o casamento? Ou a evocação do casamento e da felicidade foi apenas imagem gratuita, sem relação nenhuma com o poema e com o contexto da pergunta?

E, como eu queria achar intenções pedagógicas que possibilitassem à poesia sair do círculo que é a sua morte, provocava a mim mesma, buscando desafiar o paradoxo de "pretender que toda a cultura a que podemos chamar grosso modo literária seja um conhecimento analítico [...], discurso exclusivamente reservado ao deleite de alguns" (Jean, [199-], p. 36).

Então, retornei a Bachelard e pude, afinal, distinguir - com ele - a imaginação enquanto experiência da novidade, aberta e evasiva. Não era mais possível, depois das situaçōes vividas com as crianças, aceitá-la como a faculdade de formar imagens, pois ela é, antes, a "faculdade de deformar as imagens fornecidas pela percepção, é sobretudo a faculdade de libertar-nos das imagens primeiras, de mudar as imagens. Se não há mudança de imagens, união inesperada das imagens, não há imaginação, ação imaginante" (Bachelard, 1990, p.1, grifos do autor).

Desse modo, para o grupo que ouviu "Serenata", brincar poesia engendrou a própria ação imaginante. Esse é o componente lúdico de aprender em linguagens $s^{6}$ : brincar movendo-se na confluência de uma mente que é o próprio corpo operando.

Não surpreende que a gênese lúdica seja o aspecto mais enfatizado para justificar teoricamente o vínculo entre a infância e o poético, ou entre a infância e a poesia dos poemas. A aproximação com a tradição popular e com os processos livres de criação, distantes da discursividade linear erudita ou acadêmica, confere aos textos simplicidade estrutural e sintática, aproximando-os do receptor criança, que ainda não domina o encadeamento lógico estrutural da linguagem adulta.

Contudo, mesmo que essas relaçôes sejam íntimas e inegáveis (Melo, 1981), não se fundamentam apenas como diversão pueril. Os jogos infantis com as linguagens também envolvem riscos! Quando avançamos ao criançamento das palavras, quando nos dispomos a observar as crianças em seus encontros com os textos li-

6. Linguagem enquanto diferentes signos, não só os convencionais de uma língua articulada, considerados pelas percepções e ações sensório-motoras dos corpos e nelas envolvidos. Nesse sentido, são linguagens símbolos gráficos e plásticos; vibrações sonoras; expressões gestuais; sensações olfato-gustativas, etc. 
terários, vislumbramos a infância do poético e seu perigo: dominar a materialidade da linguagem verbal - som, silêncio e imagem - para extrair da leitura (que para as crianças não leitoras é uma escuta) aprendizagem e conhecimento, a espécie de conhecimento que repercute experiências e encontros imaginados.

Pondé (2009, [s.p.]) observa que "a iniciação ao discursivo leva a uma perda gradual da lógica emocional da infância, provocando um empobrecimento da linguagem que só será restaurado pela arte". Se pensarmos que as crianças pequenas não são artistas e, muito menos, alunos, o contato com as artes, entendidas como linguagens, poderá recuperar ou dinamizar a ação imaginante, aquilo que a aprendizagem linear da leitura e da escrita acaba por prejudicar.

Há, aqui, a afirmação de uma circularidade que escapa à lógica escolar, segundo a qual se brinca ou se aprende, mesmo afirmando o contrário. O processo da aquisição da leitura e da escrita, principalmente a ênfase na leitura da prosa, contribui para esse empobrecimento, "pois exige que se galgue palavra por palavra, numa ordem linear. Isto não acontece com a poesia que privilegia o todo e não as partes, pela própria constituição condensada da linguagem" (Pondé, 2009. [s.p.]). Na escola, e infelizmente desde a Educação Infantil, vamos submetendo o corpo que realiza a ação imaginante no mundo pela palavra que descreve e explica $o$ mundo:

Processos imagéticos de transfiguração, de transformação e instaur ação da palavra são reduzidos a processos de descrição, explicação e informação: importa é contemplar e interpretar em palavras para que, no fundo do fundo, possamos encontrar a ilusão de uma verdade. Um real descarnado que acaba tornando-se cego e vazio para o trânsito de sentidos que significam a convivência. (Richter; Fronckowiak, 2007, p.57)

Com isso, não é absurdo distinguir que, no brinquedo poesia, além do brincar, as crianças encontrem

razões importantes para crer que a aventura humana pode ser reinventada por todos [...] lendo, escutando e conservando toda a vida o que os poetas dela disseram para a descrever, a percorrer, a denunciar, a exaltar ou a explorar nas suas profundezas indizíveis. (Jean, [199-], p. 242)

Brincar a experiência de ler - a voz dos textos que se faz ouvir

No contexto da Educação Básica brasileira, o lugar destinado à leitura literária descortina concepções salvacionistas e redentoras do hábito de ler, a partir de abordagens cognitivistas escolarizadas ou intuitivas há mais de quatro décadas questionadas por pesquisadores, professores e escritores. 
Sem pretender esgotar extensa bibliografia, as análises sobre essa problemática no âmbito dos estudos literários têm seguido duas direções mais evidentes: o exame da qualidade dos suportes, dos instrumentos e dos mecanismos escolares empregados para a formação de leitores de textos verbais em diferentes níveis de ensino (Bordini, 1991; Lajolo, 1993; Soares, 1999; Zilberman, 1982) e a investigação de metodologias, políticas e instâncias de mediação para promover a leitura numa concepção mais ampla (Aguiar, 2001, 2004; Aguiar; Bordini, 1988; Bojunga, 1998; Kramer, 2000; Meireles, 1979; Paulino et al., 2001; Perrotti, 1990; Zilberman; Cademartori, 1982). É pontual - e não deve ser esquecida - a advertência de que a leitura realizada na escola, por certo, será escolar (Soares, 1999). Mas focar a aproximação com a literatura, buscando exclusivamente instrução moral, motivações para o estudo da gramática, tema para datas comemorativas ou belas e eruditas letras em um suporte como o livro didático negligencia as potencialidades que o encontro com essa linguagem pode oferecer à formação de crianças e adultos.

Conceber a aprendizagem enquanto experiência do corpo que conhece conhecendo convida a admitir a potência das linguagens enquanto dimensão poética. Nesse sentido, não experimentamos uma linguagem para depois fruirmos outra e mais outra numa sequência linear. Vivos, estamos em linguagens, sempre abertos e incompletos. Projetamos o entorno nos fazendo e nos criando, o que oferece outros sentidos para a proposição educativa da palavra pedagógica. Em relação à palavra poética, por exemplo, suscita no educador a convicção de que os textos a que as crianças pequenas têm acesso chegam a elas através da leitura do adulto, responsabilidade desafiadora nem sempre compreendida na extensão de sua amplitude.

É lendo que o professor enseja o encontro das crianças com a sua linguagem original - ainda não formatada na discursividade adulta - e a valida para a cognição que emerge da corporeidade: a compreensão como movimento e não como processamento de informaçôes. "Somos seres corporais, corpos em movimento. O movimento tem a capacidade não apenas de modificar as sensações, mas de reorganizar o organismo como um todo, considerando a unidade mente-corpo." (Nóbrega, 2005, p. 607).

A escuta regular de poemas pode conduzir as crianças à experiência de ler. Experiência entendida na acepção de Walter Benjamin (1985, 1987), que a distingue da vivência (finita) daquilo que acontece. A experiência é o que acontece a alguém e que, por ter sido sentido, pode ser narrado e compartilhado; tornado, portanto, experiência coletiva (infinita). $\mathrm{O}$ caráter não sistemático da experiência de ler a afasta das categorizações conceituais. A leitura não é um conceito, é um processo: ler.

Com von Foerster, vemos que, quando um verbo é transformado num substantivo, nos aparece de repente como se fosse um objeto. "Se estamos ante um processo que pode converter-se numa coisa, vamos por caminho errado. Muitas 
de nossas dificuldades para compreender se devem a que constantemente tratamos com objetos que, em realidade, são processos." (Foerster, 1996, p.62).

A leitura, substantivação do processo de ler, se reduz na escola ao uso de estratégias para a alfabetização, "o exercício do traço, a identificação da relação entre grafema e fonema, quantidade e número, a interação com diferentes tipos e gêneros textuais e a imersão na cultura escrita, esquecendo a implicação lúdica do movimento dos corpos em cada um desses processos" (Richter; Fronckowiak, 2007, p.57).

Embora se reitere que "a alfabetização desenvolve-se no contexto de e por meio de práticas sociais de leitura e de escrita, isto é, através de atividades de letramento" (Soares, 2004, p.10, grifos da autora), não temos debatido como essas práticas sociais se configuram no contexto escolar, onde a avidez alfabetizadora exime sistematicamente o corpo - abandonado em um não lugar -, simplificando sua complexidade cognitiva. A leitura - tanto quanto as demais linguagens: desenho, pintura, ciências da natureza, modelagem, jogos cooperativos, dança, teatro, matemática, etc., — se reduz a uma des-experiência, ou seja, à vivência estrita de técnicas descarnadas da ação imaginante. Isso constitui enorme violência com a infância, momento em que se está disponível - mais disponível do que nas demais etapas da vida - para aprender a "engendrar pensamento com outros como modo de aprender a comviver." (Richter; Fronckowiak, 2007, p.56).

Ao admitir a leitura enquanto processo de ler, alguns estudiosos estabelecem percursos produtivos, aproximando os conceitos benjaminianos de vivência/ experiência da problemática educacional, seja no âmbito conceitual da aprendizagem (Larrosa, 1996, 2002, 2004) ou no das práticas sociais da leitura e da escrita (Kramer, 2000).

Menos usuais, mas não menos relevantes, são os conceitos de repercussão e ressonância, constituintes intrínsecos do devaneio poético (Bachelard, 1993), cujo debate pode ajudar a aproximar crianças e linguagem poética. Gaston Bachelard não abordou a leitura da poesia na perspectiva das crianças, embora tenha dedicado um lindo capítulo aos devaneios adultos voltados para a infância (Bachelard, 1988).

Contudo, o aprofundamento da experiência de ler/fruir o âmago dos poemas, acionado a partir do par repercussão/ressonância, não deixa de ocorrer com crianças. Quando ouvem poemas, são envolvidas pela repercussão, fenômeno que convida "a um aprofundamento da nossa própria existência". No leitor - no caso das crianças dessa faixa etária, no ouvinte —, ela "opera uma inversão do ser. Parece que o ser do poeta é o nosso ser". Em seguida, a unidade do ser da repercussão vai possibilitar múltiplas ressonâncias que "dispersam-se nos diferentes planos de nossa vida no mundo". Dessa forma, o poema nos toma por inteiro e "sentimos um poder poético erguer-se ingenuamente em nós", pois é "depois da repercussão que podemos experimentar ressonâncias [...] sentimentais, recordações do nosso passado." (Bachelard, 1993, p. 7). 
Com o grupo de crianças citado foi possível perceber esse movimento em muitas situaçôes. Num dos encontros, perguntei se aceitavam o desafio de encontrar palavras que combinam para jogar com versos de um poema (exercício lúdico da consciência fonológica). Verbalizada a sugestão, Denise, de 5 anos, questionou de modo explicativo para o grupo: "É assim, ob: tu conhece [sic] a Marisa, aquela que te puxou a camisa?" Outros comentários denotaram a compreensão rímica das crianças, inclusive a afirmação de Henrique, que seguia trilha distinta: "Que nem tem a manga de comer e a manga da camisa, né?" A professora da turma explicou que eles pesquisavam para produzir um livro com palavras irmãs, palavras que são iguais para falar e, às vezes, para escrever ${ }^{7}$, mas que indicam coisas diferentes. Depois da explicação, retomei a brincadeira, mas as crianças ainda falavam, querendo manifestar seu entendimento do tipo de jogo proposto, ou seja, compartilhando que já sabiam o que era uma rima:

Eu, a Luiza e a Bianca, a gente sempre inventa palavras assim na nossa casa e aqui na escola. (Natália, 5 anos).

Que legal! (eu)

E eu também já sei várias coisas que é bem igual, tipo banana, bananeira e carro, carroceiro - (Matheus, 5 anos).

Ah, mas isso é outra boa invenção - (eu)

A observação de Matheus trouxe para a roda a música "Pomar", referente poético da sua repercussão, composição de apenas uma estrofe do CD Cançôes de brincar, que as crianças ouviam com muita frequência na escola e que ele adorava, na qual Paulo Tatit e Sandra Peres expõem o encadeamento fruta/árvore frutífera nos versos. Ao ser encorajado a verbalizar sua compreensão sobre rimas, o menino reproduziu o mecanismo de derivação que constitui a canção, em virtude das repercussões poéticas que a música lhe sugeria. Mas ousou uma nova possibilidade associativa ("carro - carroceiro") ao repertório de experiências sonoras que possuía.

Embora a derivação criada não seja exemplar na linguagem padrão, ela demonstra a introjeção da lógica semântica do texto pelo menino, que associa carroceiro a carro, palavras que têm a mesma raiz etimológica. Depois, deixa revelar o proveito da regra fonológica, pois, para realizar a rima, submeteu a palavra carro à convenção empregada nas demais palavras da canção. Matheus não só sabia o

7. Felizmente, a professora fazia referência de forma ilustrativa à escrita, mesmo as crianças não sendo alfabetizadas, o que nos mostra as práticas de letramento a que crianças e adultos estão imersos, desde sempre, numa sociedade letrada.

8. "Pomar": Banana, bananeira/ Goiaba, goiabeira/ Laranja, laranjeira/ Maçã, macieira/ Mamão, mamoeiro/ Abacate, abacateiro/ Limão, limoeiro/ Tomate, tomateiro/ Caju, cajueiro/ Umbu, umbuzeiro/ Manga, mangueira/ Pera, pereira/ Amora, amoreira/ Pitanga, pitangueira/ Figo, figueira/ Mexerica, mexeriqueira/ Açaí, açaizeiro/ Sapoti, sapotizeiro/ Mangaba, mangabeira/ Uva, parreira/ Coco, coqueiro/Ingá, ingazeiro/ Jambo, jambeiro/ Jabuticaba, jabuticabeira. 
que era uma rima como também ultrapassou a compreensão da "identidade de sons a partir da vogal tônica da última palavra de dois ou mais versos" (Trevisan, 2001, p. 118). Ele internalizou o mecanismo linguístico que, na música "Pomar", sustenta o ritmo dos versos, estendendo-o a um referente de ressonância masculina infantil, os carros.

A canção repercutida pelo menino nas muitas experiências de sua audição na escola transformou-se e surgiu como proposta de sentido para mais uma experiência pessoal: falar sobre rimas para alguém que entendia do assunto, a profe da poesia. Encantado pela música, Matheus desejou contar sobre seu envolvimento com as "várias coisas que ébem igual" que ele também já sabia. Bachelard (1988, p. 3) sintetiza poeticamente o processo: "Ao maravilhamento acrescenta-se, em poesia, a alegria de falar”, um falar que, como já argumentei, não é narrativo, mas ficcional.

A escuta de textos conduz as crianças à experiência poética de ler, predispondo à repercussão e à ressonância através da ação imaginante. $\mathrm{O}$ argumento, se aceito, traz à tona o tema hermenêutico da compreensão da linguagem, problema intrínseco a toda interpretação literária, com a ressalva de que o processo para as crianças não leitoras se gesta na e a partir $d a$ ação oral do mediador adulto - professor ou familiar.

Essa posição é pouco destacada nos estudos literários, que procuram conceber os textos - acertadamente - em sua imanência - excluindo dados biográficos, históricos ou psicológicos como determinantes diretos de seu conteúdo semântico. Partem da premissa de que o "próprio texto tem o seu ser nas palavras, no seu arranjo, nas suas intenções e nas intenções da obra de uma determinada espécie" (Palmer, 1989, p. 28). Assim, buscam preservar no texto sua integridade, livrandoo da heresia da paráfrase.

A posição é inequívoca. Ler um texto literário é nele encontrar sentidos, excluindo inferências ou analogias à vida factual ou psicológica do seu autor. Não é insânia, contudo, reconhecer que a autonomia do texto resguarda - ainda - uma existência oral, acontecimento no tempo que transporta as palavras para além de suas acepções visuais e conceituais. As palavras escritas que lemos são palavras-eventos, desempenhos orais corporificados, mas silenciosos. Há uma voz que fala e se inscreve no texto. Sua escuta será uma forma disfarçada da leitura oral. Para as crianças, esse desempenho oral terá uma instância intermediária: a voz do adulto leitor.

O ponto de vista do leitor que ouve a voz silenciosa do texto foi defendido por Paul Zumthor, ao estudar a literatura medieval. Para ele, "poesia" é arte da linguagem humana, fundamentada em estruturas antropológicas profundas, independente de seus modos de concretização. $\mathrm{O}$ autor desviou-se do estudo específico do texto literário e partiu "empiricamente do que poderia ser ponto de chegada (a percepção sensorial do 'literário' por um ser humano real) para poder induzir alguma proposição sobre a natureza do poético [...] interrogando [...] o papel do corpo na leitura e na percepção do literário." (Zumthor, 2007, p. 23). Ele afirma: 
"coloco-me no ponto de vista do leitor, mais do que da leitura, no sentido em que esta palavra designa abstratamente uma operação. O que eu questiono é o leitor lendo, operador da ação de ler." (Ibidem, p. 24).

Para os pequenos (e os grandes que deles se ocupam), implicar as percepções sensoriais da ação de ler à interpretação poética da poesia é, sem dúvida, considerar os efeitos da voz de cujo corpo ela emana de forma plena. Para Zumthor, esse processo está envolvido na prática da leitura literária através da noção de performance? .

A performance é sempre constitutiva da forma. Suas regras pragmáticas "importam para a comunicação tanto ou ainda mais do que as regras textuais postas na obra na seqüência das frases: destas elas engendram o contexto real e determinam finalmente o alcance." (Zumthor, 2007, p. 30). Por isso Zumthor distinguiu obra e texto. A obra compreende a totalidade de fatores da performance que são poeticamente comunicados no aqui e no agora: texto, sonoridades, ritmos, elementos visuais. $\mathrm{O}$ texto é a sequência linguística que tende ao fechamento, cujo sentido global não é redutível à soma dos efeitos de sentidos particulares produzidos por seus sucessivos componentes. O poema seria, então, o texto, recuperável e legível, mas destituído de seus aspectos audíveis e visíveis da performance (Zumthor, 1993, p. 220).

Então, se, através dos textos, não podemos mais acessar a obra - pois todos os textos que lemos partem de uma escrita primeira -, será o prazer do corpo sentindo a emoção do texto que sintetizará a resistência da atitude performática. $\mathrm{O}$ "que na performance oral pura é realidade experimentada, na leitura é da ordem do desejo." (Zumthor, 2007, p. 35). Assim, hoje, há uma inversão em relação à performance medieval: o prazer individual da experiência de ler engendra o ritual coletivo no fim do percurso. E a criança, através de sua ação imaginante a um só tempo ficcional e corpórea, mostra isso.

\section{Brincar o processo de ensinar ensinando: ler as crianças lendo}

No cenário educacional brasileiro, temos acompanhado o debate sobre que currículo propor para as escolas de Educação Infantil, levando em conta o fato de que também acolhem crianças de 0 a 3 anos. Pesquisadores e professores têm desejado - e argumentado nesse sentido — que essas escolas, seguindo as orientações das diretrizes nacionais e respaldadas no direito à elaboração de suas propostas autônomas, considerem seu dever de abordar o conhecimento em uma concepção mais complexa do que aquela que o fragmenta em conteúdos disciplinares ou áreas do conhecimento. Essa complexidade, entretanto, não é sinônima de sisudez.

9. O termo, emprestado à dramaturgia entre os anos 1930 e 40, se espalhou nos EUA, relacionado a diferentes manifestações culturais lúdicas, como contos, canções, ritos, danças, etc. Zumthor utilizou o termo no estudo que fez da literatura medieval, obviamente uma literatura que agregava mais elementos do que apenas o texto verbal. 
A comunidade educativa - que não se restringe à escolar - tem a responsabilidade de garantir às crianças de 0 a 6 anos o acesso à cultura em espaços públicos de socialização, mas também a de preservar as especificidades lúdicas da ação imaginante contidas nas práticas educativas oferecidas para essa faixa etária distanciada de uma concepção curricular prescritiva.

Para as crianças que iniciam sua trajetória leitora, explorar o poético na ação imaginante do encontro das linguagens traça outras perspectivas para a abordagem das diferentes manifestações culturais na escola. Primeiramente, desenha percursos de formação para o professor da infância que enfatizam a leitura enquanto processo de ler, experiência complexa distante da ideia de estudo exclusivo do texto verbal escrito (acabado, linear, silencioso e imóvel). Esse percurso fundamentará recursos para a superação do emprego da voz numa perspectiva oral e sua construção enquanto artefato vocal. Assim, o pacto de sentido proposto ao leitor através da fala do narrador ou do eu poético - no caso da poesia - será iluminado pela vocalização de viva voz do adulto, leitura-expressão interpretativa capaz de projetar a performance da obra para a criança, o leitor ouvinte.

Em segundo lugar, há a possibilidade de minimizar a ênfase na distinção de textos por gênero, faixas etárias, temáticas, períodos de desenvolvimento, etc. Como as crianças ainda não leem, necessitam da voz do adulto para experimentar os sentidos de prazer do texto, independentemente de este se apresentar como uma narrativa, um poema - tipologia textual mais associada à oralidade -; de ser longo, curto, etc. Será o grupo e suas experiências que orientarão escolhas e ênfases. Nesse sentido e a título de exemplo, as experiências relacionadas tanto à escuta do poema "Serenata" quanto à da canção "Pomar" não foram decorrentes exclusivas do sentido da audição, nem de um planejamento fechado e propositivo a partir do estudo daqueles textos.

Em seguida, estar intencionalmente em linguagens é poder abandonar dois grandes constrangimentos pedagógicos. Primeiro, o de insistir - por deferência irrestrita ao sistema literário e à gramática - na ênfase no texto, cuja apreensão das intenções decorreria da contenção de corpos e movimentos, ou seja, de preterir as crianças à aprendizagem. Além desse, o constrangimento de pretender - pela superfaturação do sujeito que aprende - eliminar obstáculos à compreensão, empregando práticas irrefletidas para alcançar efeitos poéticos nem sempre úteis à fruição. Nesse caso, em respeito à aprendizagem das crianças, se aligeira a construção cognitiva de que o texto tem também um sentido em si mesmo.

Com Barbosa (2009, p. 81), defendo que são as práticas sociais - diretas e indiretas - de cuidado e de educação que se configuram como primeiras experiências curriculares das crianças. Assim,

através de gestos, toques, palavras, modos de organização de vida e ritmo cotidiano, oferecemos a elas [...] experiências 
que são [...] incorporadas em seus modos de olhar, balbuciar, escutar, imitar e que, posteriormente, [...] configurarão seu modo singular de viver e conviver em grupo.

Educar é desejar educar-se, o que exige o esforço da atenção sobre como observamos, acolhemos, validamos e ouvimos aquilo que as crianças nos dizem, tanto quando aprendem, quanto quando se negam a fazê-lo. Ler as crianças lendo é fabular e agir de maneira imaginante sobre o fundo temporal da história. Ler as crianças lendo é apreender o ficcional da educação que dá certo, do mesmo modo como, nesse texto, eu apreendi a mim.

\section{Referências bibliográficas}

AGUIAR, V. T. de. O verbal e o não verbal. São Paulo: Unesp, 2004.

AGUIAR, V. T. (Coord.) Era uma vez... na escola: formando educadores para formar leitores. Belo Horizonte: Formato, 2001.

AGUIAR, V. T. de; BORDINI, M. G. Literatura - a formação do leitor: alternativas metodológicas. Porto Alegre: Mercado Aberto, 1988.

BACHELARD, G. A poética do devaneio. São Paulo: Martins Fontes, 1988.

BACHELARD, G. O ar e os sonhos: ensaio sobre a imaginação do movimento. São Paulo: Martins Fontes, 1990.

BACHELARD, G. A poética do espaço. São Paulo: Martins Fontes, 1993.

BARBOSA, M. C. Práticas cotidianas na educação infantil - bases para a reflexão sobre as orientações curriculares. Brasília: Ministério da Educação, Universidade Federal do Rio Grande do Sul, 2009. Disponível em: http://portal.mec.gov.br/dmdocuments/relat_seb_ praticas_cotidianas.pdf. Acesso em: 4 ago. 2010.

BARROS, M. de. Livro sobre nada. Rio de Janeiro: Record, 1997.

BENJAMIN, W. Magia e técnica, arte e política: ensaios sobre literatura e história da cultura. 7. ed. São Paulo: Brasiliense, 1985. (Obras escolhidas, v.1).

BENJAMIN, W. Rua de mão única. 2. ed. São Paulo: Brasiliense, 1987. (Obras escolhidas, v. 2).

BOJUNGA, L. Livro, um encontro com Lygia Bojunga. 4. ed. Rio de Janeiro: Agir, 1998.

BORDINI, M. G. Poesia infantil. 2. ed. São Paulo: Ática, 1991.

CAPPARELLI, S. Tigres no quintal. Porto Alegre: Kuarup, 1989.

FOERSTER, H. von. Visão e conhecimento: disfunções de segunda ordem. In:

SCHNITMAN, D. F. (Org.). Novos paradigmas, cultura e subjetividade. Porto Alegre: Artes Médicas, 1996, p. 59-74. 
JEAN, G. Na escola da poesia. Lisboa: Instituto Piaget, [199-].

KRAMER, S. Leitura e escrita como experiência - seu papel na formação de sujeitos sociais. Presença Pedagógica. v. 6, n. 31, jan./fev. 2000. Disponível em: http://www. presencapedagogica.com.br/capa6/artigos/31.pdf . Acesso em: 10 maio 2010.

LAJOLO, M. Do mundo da leitura para a leitura do mundo. São Paulo: Ática, 1993.

LAROSSA, J. La experiencia de la lectura: estudios sobre literatura y formación. Barcelona: Laertes, 1996.

LAROSSA, J. Notas sobre a experiência e o saber de experiência. Tradução João Wanderley Geraldi. Revista Brasileira de Educação, Rio de Janeiro, n. 19, p. 20-28, jan./fev./mar./abr. 2002.

LAROSSA, J. Linguagem e educação depois de Babel. Tradução Cynthia Farina. Belo Horizonte: Autêntica, 2004.

MEIRELES, C. Problemas da literatura infantil. 2. ed. São Paulo: Summus, 1979.

MELO, V. de. Folclore infantil. Rio de Janeiro: Cátedra, Brasília: INL, 1981.

NÓBREGA, T. P. da. Qual o lugar do corpo na educação? Notas sobre conhecimento, processos cognitivos e currículo. Educação \& Sociedade. Campinas, v. 26, n. 91, p. 599615, maio/ago. 2005.

PALMER, R. Hermenêutica. Lisboa: Ediçōes 70, 1989.

PAULINO, G. et al. Tipos de textos, modos de leitura: Belo Horizonte: Formato, 2001.

PERROTTI, E. Confinamento cultural, infância e leitura. São Paulo: Summus, 1990.

PONDÉ, G. M. F. Poesia para crianças: a mágica da eterna infância. Tigre Albino. v. 2, n. 2, mar. 2009. ISSN 1982-9434. Disponível em: http://www.tigrealbino.com.br/texto. Acesso em: 15 maio 2010.

POUND, E. A arte da poesia: ensaios escolhidos. 2. ed. São Paulo: Cultrix, 1988.

POUND, E. Abc da literatura. São Paulo: Cultrix, [198-].

RICHTER, S.; FRONCKOWIAK, A. Alfabetização, letramento e experiência poética: a seriedade da alegria. In: FERREIRA, V. S. (Org.). Infância e linguagem escrita: práticas docentes. Itajaí: Universidade do Vale do Itajaí, 2007.

SOARES, M. A escolarização da leitura infantil e juvenil. In: BRANDÃO, M. B.; EVANGELISTA, A. A. M.; MACHADO, M. Z. V. (Org.) A escolarização da leitura literária: o jogo do livro infantil e juvenil. Belo Horizonte: Autêntica, 1999.

SOARES, M. Letramento e alfabetização: as muitas facetas. Revista Brasileira de Educação, n. 25, p. 5-17, jan./fev./mar./abr. 2004.

TREVISAN, A. A poesia: uma iniciação à leitura poética. 2. ed. Porto Alegre: Secretaria Municipal da Educação, Secretaria Municipal da Cultura, Uniprom, 2001.

ZILBERMAN, R. A literatura infantil na escola. 2. ed. São Paulo: Global, 1982. 
ZILBERMAN, R.; CADEMARTORI, L. Literatura infantil: autoritarismo e emancipação. São Paulo: Ática, 1982.

ZUMTHOR, P. A letra e a voz: a literatura medieval. Companhia das Letras, 1993.

ZUMTHOR, P. Performance, recepção, leitura. São Paulo: Cosac Naify, 2007.

Recebido em 22 de dezembro de 2010 e aprovado em 25 de março de 2011. 